\title{
Effect of immediate and delayed dentin sealing on the fracture strength, failure type and Weilbull characteristics of lithiumdisilicate laminate veneers
}

\author{
Gresnigt, Marco M M ; Cune, Marco S ; de Roos, Joanne G ; Özcan, Mutlu
}

\begin{abstract}
OBJECTIVES Adhesion on dentin is less reliable than on enamel, which could affect the durability of laminate veneers (LV). Immediate dentin sealing (IDS) is suggested instead of delayed dentin sealing (DDS) to overcome hypersensitivity and prevent debonding from dentin. This study evaluated the effect of IDS and DDS on the durability of Li2Si2O5 laminate veneers in vitro. METHODS Window preparations were made on the labial surfaces of sound maxillary central incisors $(\mathrm{N}=50)$. They were randomly divided into five groups: Group 1 : Enamel only+H3PO4+Adhesive (control); Group 2: $<1 / 4$ dentin+H3PO4+DDS (2 weeks later); Group 3: Complete dentin+H3PO4+DDS (2 weeks later); Group 4: <1/4 dentin+H3PO4+IDS; Group 5: Complete dentin+H3PO4+IDS. Li2Si2O5 laminate veneers (e.max Press) were bonded to the labial surfaces of the teeth with adhesive resin cement (Variolink Veneer). IDS layers were silicacoated (CoJet System) and silanized (ESPE-Sil). The teeth with their bonded laminates were thermocycled $(10.000 \times$ cycles $)$ and then subjected to static loading $(1 \mathrm{~mm} / \mathrm{min})$. Failure type and location after debonding were classified. Data were analyzed using ANOVA and Tukey's post hoc test $(\alpha=0.05)$. Two-parameter Weibull distribution values including the Weibull modulus, scale $(\mathrm{m})$ and shape (0), values were calculated. RESULTS Mean fracture strength $(\mathrm{N})$ per group in descending order was as fol-

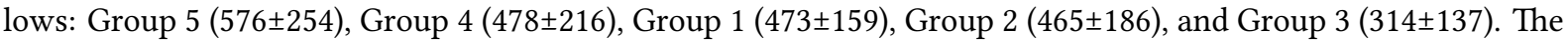
presence of complete dentin exposure sealed with DDS after 2 weeks on the bonded surface (Group 3) resulted in significantly lower fracture strength results than those in group 5 with IDS $(\mathrm{p}=0.034)$. Weibull distribution presented higher shape (0) for Group 1 (3.67), than those of other groups (2.51-2.89). Failure types were predominantly adhesive failure between the cement and the laminate veneer in Groups 1, 2, 4 whereas Group 3 presented more often complete adhesive failures between the cement and dentin. In Group 5, failures showed some IDS and cement with or without ceramic fracture attached on the tooth. SIGNIFICANCE When laminate veneers are bonded to a large dentin substrate, application of immediate dentin sealing improves adhesion and thereby, the fracture strength of $\mathrm{Li} 2 \mathrm{Si} 2 \mathrm{O} 5$ laminate veneers.
\end{abstract}

DOI: https://doi.org/10.1016/j.dental.2016.01.001

Posted at the Zurich Open Repository and Archive, University of Zurich

ZORA URL: https://doi.org/10.5167/uzh-127845

Journal Article

Accepted Version

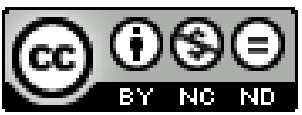

The following work is licensed under a Creative Commons: Attribution-NonCommercial-NoDerivatives 4.0 International (CC BY-NC-ND 4.0) License.

Originally published at: 
Gresnigt, Marco M M; Cune, Marco S; de Roos, Joanne G; Özcan, Mutlu (2016). Effect of immediate and delayed dentin sealing on the fracture strength, failure type and Weilbull characteristics of lithiumdisilicate laminate veneers. Dental Materials, 32(4):e73-e81.

DOI: https://doi.org/10.1016/j.dental.2016.01.001 
Effect of Immediate and Delayed Dentin Sealing on the Fracture Strength, Failure Type and Weilbull Characteristics of Lithiumdisilicate Laminate Veneers

\author{
Marco M.M. Gresnigt,,${ }^{a}{ }^{,}$Marco S. Cune, ${ }^{a}$ Joanne G. de Roos,,${ }^{a}$ Mutlu Özcan ${ }^{b}$
}

${ }^{a}$ University Medical Center Groningen, The University of Groningen, Groningen, Center for Dentistry and Oral Hygiene, Department of Fixed and Removable Prosthodontics, The Netherlands

${ }^{b}$ University of Zurich, Dental Materials Unit, Center for Dental and Oral Medicine, Clinic for Fixed and Removable Prosthodontics and Dental Materials Science, Zurich, Switzerland

Short title: Effect of immediate dentin sealing on durability of laminate veneers

*Corresponding author:

Dr. Marco Gresnigt

Department of Fixed and Removable Prosthodontics

Center for Dentistry and Oral Hygiene

University Medical Center Groningen

The University of Groningen

Antonius Deusinglaan 1

9713 AV, Groningen

The Netherlands

Tel: +31-50-363-2608; fax: +31-50-363-2696

E-mail address: marcogresnigt@yahoo.com (M. Gresnigt) 


\section{ABSTRACT}

Objectives. Adhesion on dentin is less reliable than on enamel, which could affect the durability of laminate veneers (LV). Immediate dentin sealing (IDS) is suggested instead of delayed dentin sealing (DDS) to overcome hypersensitivity and prevent debonding from dentin. This study evaluated the effect of IDS and DDS on the durability of $\mathrm{Li}_{2} \mathrm{Si}_{2} \mathrm{O}_{5}$ laminate veneers in vitro.

Methods. Window preparations were made on the labial surfaces of sound maxillary central incisors $(\mathrm{N}=50)$. They were randomly divided into five groups: Group 1: Enamel only $+\mathrm{H}_{3} \mathrm{PO}_{4}+$ Adhesive (control); Group 2: $<1 / 4$ dentin $+\mathrm{H}_{3} \mathrm{PO}_{4}+\mathrm{DDS}$ (2 weeks later); Group 3: Complete dentin $+\mathrm{H}_{3} \mathrm{PO}_{4}+\mathrm{DDS}$ (2 weeks later); Group 4: $<1 / 4$ dentin $+\mathrm{H}_{3} \mathrm{PO}_{4}+$ IDS; Group 5: Complete dentin $+\mathrm{H}_{3} \mathrm{PO}_{4}+$ IDS. $\mathrm{Li}_{2} \mathrm{Si}_{2} \mathrm{O}_{5}$ laminate veneers (e.max Press) were bonded to the labial surfaces of the teeth with adhesive resin cement (Variolink Veneer). IDS layers were silicacoated (CoJet System) and silanized (ESPE-Sil). The teeth with their bonded laminates were thermocycled ( $x 10.000$ cycles) and then subjected to static loading $(1 \mathrm{~mm} / \mathrm{min})$. Failure type and location after debonding were classified. Data were analyzed using ANOVA and Tukey`s post-hoc test $(\alpha=0.05)$. Two-parameter Weibull distribution values including the Weibull modulus, scale $(m)$ and shape $(0)$, values were calculated.

Results. Mean fracture strength (N) per group in descending order was as follows:

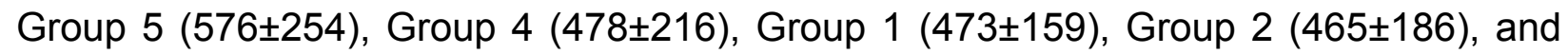
Group $3(314 \pm 137)$. The presence of complete dentin exposure sealed with DDS after 2 weeks on the bonded surface (Group 3) resulted in significantly lower fracture strength results than those in group 5 with IDS $(p=0.034)$. Weibull distribution presented higher shape (0) for Group 1 (3.67), than those of other groups (2.51-2.89). Failure types were predominantly adhesive failure between the cement and the laminate veneer in Groups 1, 2, 4 whereas Group 3 presented more often complete adhesive failures between the 
cement and dentin. In Group 5, failures showed some IDS and cement with or without ceramic fracture attached on the tooth.

Significance. When laminate veneers are bonded to a large dentin substrate, application of immediate dentin sealing improves adhesion and thereby, the fracture strength of $\mathrm{Li}_{2} \mathrm{Si}_{2} \mathrm{O}_{5}$ laminate veneers.

Keywords: Adhesion; Bonding; Cementation; Ceramic; Dentin; Immediate Dentin Sealing; Laminate; Veneer 


\section{Introduction}

Laminate veneers in particular entail minimal tooth preparation of only 0.3 to 0.9 $\mathrm{mm}$, which is highly conservative when compared to their full-coverage crown alternative. Although preparation for laminate veneers could be achieved within the vicinity of enamel, some dentin exposure, especially at the cement-enamel junction or below in the cervical area, is sometimes unavoidable [1-3]. Freehand preparation of such restorations, without the use of putty indices or guiding grooves of depth may yield to deeper preparations with higher amount of dentin exposure [2]. Preparation depth may in fact have consequences on the final fracture strength of minimal invasive restorations, in that lower fracture strength results were reported for laminate veneers when bonded to dentin compared to enamel [4]. Unfortunately, clinical studies on survival of laminate veneers do not often report whether preparations were solely in enamel or dentin. Yet, available evidence from clinical studies that reported dentin exposure after tooth preparation, also reported higher incidence of failures [5-8]. Recently, a review on the clinical evaluation of laminate veneers bonded to dentin concluded that the survival rate diminished when such restorations were bonded to dentin [9].

In order to prevent micro-leakage and hypersensitivity, sealing of the dentin prior to impression taking for the indirect restorations was advocated in early 1990ies [10]. In addition, other studies concluded that adhesive strength of restorations was improved when dentin was sealed [11-15]. Adhesive strength after this so called immediate dentin sealing (IDS) was compared with the conventional adhesive cementation, delayed dentin sealing (DDS), which is a common procedure for cementation of fixed dental prosthesis. In these studies, bond strength results employing DDS varied between 2 to $12 \mathrm{MPa}$, whereas application of IDS resulted in significantly higher mean bond strength results between 15 and $58 \mathrm{MPa}$ depending on the test method [12,14-16]. Apparently, 
application of the adhesive resin on freshly cut dentin and further polymerization of the adhesive resin over time improved adhesion of bonded restorative materials $[17,18]$. Furthermore, it was also postulated that application of IDS results in a smooth surface that also improves the adaptation of the indirect restorations [19].

Clinical studies on the survival rate of laminate veneers bonded onto teeth with existing resin composite restorations did not show encouraging results, providing that the substrate surfaces were not conditioned [6-8]. However, in an in vitro study, ceramic laminate veneers bonded to a complete composite surface presented higher fracture strength results than those bonded onto enamel [20]. Similarly, clinical survival rate of laminate veneers bonded onto teeth with existing composite restorations after the latter was tribochemical silicacoated, was not less than those bonded on enamel/dentin up to 40 months of evaluation [21]. Thus, it can be anticipated that the presence of adhesive resin would also not impair the bond strength of laminate veneers on the IDS.

The objectives of this study therefore were to a) compare the fracture strength of laminate veneers with and without IDS application, b) evaluate the influence of the size of the exposed dentin and c) failure types after loading until fracture. The first hypothesis tested was that the presence of IDS would positively contribute to the fracture strength of the laminate veneer compared to conventional adhesive cementation (DDS). The second hypothesis tested was that the size of exposed dentin would not decrease the fracture strength of the laminate veneers.

\section{Material and methods}

\subsection{Specimen preparation}

The brands, types, main chemical compositions, manufacturers and batch numbers of the materials used for the experiments are listed in Table 1. Schematic description of the experimental design is presented in Fig. 1. 
Sound human central incisors $(\mathrm{N}=50)$ of similar size, free of restorations and root canal treatment were selected from a pool of recently extracted teeth. All teeth were screened on the presence of cracks by blue light and those with cracks were eliminated and replaced with new teeth. Before a laminate veneer preparation was made, impressions were made using a high precision condensation silicone (Provil Novo putty fast set, Heraeus, Hanau, Germany) in order to obtain moulds for the provisionals. Window type of tooth preparations without incisal overlap, were made with a depthcutting bur (801 201SC Swiss Dental Products, Intensiv Grancia, Switzerland), with this preparation type adhesion of the laminate did not rely on the macro-mechanical retention as in the case of overlap preparations. After the depth cuts of $0.3 \mathrm{~mm}$ were made, preparation was finalized using a round-ended tapered diamond chamfer bur (Swiss Dental Products, FG-2309). The preparations ended $1 \mathrm{~mm}$ above the cementenamel junction.

The amount of dentin exposure was controlled by etching the prepared surface for 5 seconds and rinsing with water that resulted in a white, dull enamel surface. Thereafter photos of the teeth were analysed and surface area of exposed dentin measured using a custom-made image program (Plaqeval, BME BioMedical Engineering, University of Groningen). Preparation margins remained in enamel in all groups. Smooth margins were created to prevent stress concentration zones using finishing discs (Sof-Lex Contouring and Polishing Discs, 3M ESPE, St Paul, Minnesota, USA).

\subsection{Experimental groups, IDS and DDS layers}

The teeth were than randomly divided into 5 groups.

Group 1: Preparation was made only in enamel. This group acted as the control group.

Group 2: In this group, next to enamel, $<1 / 4$ of the cervical dentin surface was exposed. Two weeks later, DDS was created. 
Group 3: In this group, dentin was exposed on the complete surface. DDS was created as in Group 2 after 2 weeks.

Group 4: In this group, next to enamel, $<1 / 4$ of the cervical dentin surface was exposed. The IDS was achieved immediately after tooth preparation. Dentin was etched with $37 \% \mathrm{H}_{3} \mathrm{PO}_{4}$ (Total-etch, Ivoclar Vivadent, Schaan, Liechtenstein) for $10 \mathrm{~s}$ followed by $30 \mathrm{~s}$ of rinsing with copious water. Then, primer and adhesive resin (Optibond FL, Kerr, Orange, USA) was applied, air-thinned and photo-polymerized for $10 \mathrm{~s}$ using an LED polymerization device (Bluephase, Ivoclar Vivadent) from a distance of $2 \mathrm{~mm}$. The output of the polymerization device was $1000 \mathrm{~mW} / \mathrm{cm}^{2}$ throughout the experiment (Bluephasemeter, Ivoclar Vivadent). After application of glycerine gel, the surface was again photo polymerized for $40 \mathrm{~s}$. IDS layer was controlled on presence of voids and excess adhesive resin was removed under the microscope (Opmipico, Zeiss, Oberkochen, Germany).

Group 5: In this group, dentin was exposed on the complete surface. The IDS was achieved as in Group 4.

Impressions of the preparations were made using a high precision silicon impression material (Prestige light, Vanini Dental Industry, Grassina, Italy). Then provisional laminates (Protemp 4, 3M ESPE, St Paul, Minnesota, USA) were made and applied using a spot etch technique where etching was performed for $10 \mathrm{~s}$ in the middle of the preparation. In Groups 4 and 5 spot etching was performed at the enamel margins and glycerine gel was applied in order to prevent adhesion between de IDS and the provisional restoration. After adjusting the temporary restorations using polishing discs (Sof-Lex Countouring and Polishing Disks, 3M ESPE), specimens were stored in distilled water at $37^{\circ} \mathrm{C}$ for 2 weeks.

One dental technician fabricated lithium disilicate $\left(\mathrm{Li}_{2} \mathrm{Si}_{2} \mathrm{O}_{5}\right)$ laminate veneers (IPS e.max Press, Ivoclar Vivadent) according to the instructions of the manufacturer. 
Veneers were first sintered in a ceramic oven (Programat P3000, Ivoclar Vivadent) and glazed. The total thickness of the laminate veneers was $0.6 \mathrm{~mm}$.

\subsection{Adhesive cementation}

A photo-polymerizing resin cement (Variolink Veneer, Ivoclar Vivadent) was used for cementation of the ceramic laminate veneers. A three-step bonding procedure with separate conditioning of the IDS layer was employed to ensure adhesion. Before cementation, provisional restoration was removed; tooth was cleaned with pumice and the fit of ceramic laminate veneers controlled under optical microscope (Zeiss Supra V50, Carl Zeiss, Oberkochen, Germany) (x10).

Cementation surfaces of the ceramic veneers were conditioned using hydrofluoric acid (Ceramic etching gel $<5 \%$ hydrofluoric acid, Ivoclar Vivadent) for 20 seconds, rinsed and ultrasonically cleaned (Emag, Valkenswaard, The Netherlands) in distilled water for 5 minutes. They were then silanized (Monobond Plus, Ivoclar Vivadent), adhesive resin was applied (Heliobond, Ivoclar Vivadent).

In Groups 1-3, teeth were etched with $37 \% \mathrm{H}_{3} \mathrm{PO}_{4}$ (Total-etch, Ivoclar Vivadent), where enamel was etched for $30 \mathrm{~s}$ and dentin for $10 \mathrm{~s}$ followed by rinsing with copious water. Primer (Syntac Primer, Ivoclar Vivadent) was applied on the dentin and adhesive resin on the whole preparation (Syntac Adhesive and Heliobond, Ivoclar Vivadent).

In Groups 4 and 5, IDS layer was silica coated (CoJet, 3M, ESPE) using a chairside air-abrasion device (Dento-PrepTM, RØNVIG A/S, Daugaard, Denmark) from a distance of $10 \mathrm{~mm}$, angle of 45 degrees at 2 bar pressure until the surface became matt. Then enamel was etched with $37 \% \mathrm{H}_{3} \mathrm{PO}_{4}$ for $30 \mathrm{~s}$ and rinsed. Silane (ESPE-Sil, 3M, ESPE) was applied at the silica-coated IDS surfaces, followed by adhesive resin application (Syntact Adhesive and Heliobond, Ivoclar Vivadent) on the whole preparation. 
Laminate veneers were cemented using photo-polymerizing cement (Variolink Veneer, Ivoclar Vivadent). Excess cement was removed using microbrushes, glycerine gel was applied at the margins of the laminate veneers and photo-polymerized for $40 \mathrm{~s}$ from labial, lingual and incisal ( $\geq 1000 \mathrm{~mW} / \mathrm{cm}^{2}$, Bluephase, Ivoclar Vivadent). Cement interface at the margins was polished using rubber points (Astropol, Ivoclar Vivadent).

\subsection{Aging and fracture test}

All specimens were thermocycled (Willytec, Munich, Germany) for 10.000 times between $5^{\circ} \mathrm{C}$ and $55^{\circ} \mathrm{C}$ with a dwell time of $30 \mathrm{~s}$ in each bath. After aging, digital photos of the specimens were made. The teeth with the cemented laminate veneers were embedded perpendicularly in polymethylmethacrylate (Autoplast, Condular, Wager, Switzerland) up to the cemento-enamel junction in the middle of the plastic rings (PVC, diameter: $2 \mathrm{~cm}$, height: $1 \mathrm{~cm}$ ).

The fracture test was performed in a Universal Testing Machine (Zwick ROELL Z2.5MA, 18-1-3/7, Zwick, Ulm, Germany). In order to simulate the clinical situation as closely as possible, the specimens were mounted onto a metal base and load was applied at $137^{\circ}$ at a crosshead speed of $1 \mathrm{~mm} / \mathrm{min}$ from the incisal direction to the laminate-tooth interface (Fig. 2). The maximum force to produce fracture was recorded.

\subsection{Failure analysis}

Failure sites were initially observed using an optical microscope (Zeiss Supra V50, Carl Zeiss) and classified as follows: Type I: Cohesive ceramic fracture; Type II: Adhesive failure between the cement and ceramic; Type III: Adhesive failure between the cement and enamel; Type IV: Adhesive failure between the cement/IDS and dentin; Type V: Adhesive failure between the IDS/cement and cement; Type VI: Tooth fracture.

Additionally, in order to observe the structural changes on the dentin or IDS, after cleansing with alcohol, two further specimens from each group were first sputter-coated with a $3 \mathrm{~nm}$ thick layer of gold (80\%) / palladium (20\%) (90 s, 45mA; Balzers SCD 030, 
Balzers, Liechtenstein) and analyzed using cold field emission Scanning Electron Microscope (SEM) (LEO 440, Electron Microscopy Ltd, Cambridge, UK). Images were made at $25 \mathrm{kV}$ at a magnification of $\times 500$ to $\times 5000$.

\subsection{Statistical analysis}

To test whether or not the data were normally distributed, skewness and kurtosis were investigated, Shapiro-Wilk tests were performed and normal $Q-Q$ plots were produced and analysed for all groups. The data appear a little skewed and kurtotic, but they do not differ significantly from normality in any of the groups $(p>0.05)$. Consequently, one-way analysis of variance (ANOVA) and Tukey's honestly significant difference (HSD) post-hoc tests were anticipated to identify possible differences between the groups, using a standard statistical programme (SPSS, PASW statistics 18.0.3, Quarry Bay, Hongkong, China). Maximum likelihood estimation without a correction factor was used for 2-parameter Weibull distribution, including the Weibull modulus, scale $(m)$ and shape $(0)$, to interpret predictability and reliability of interfacial adhesion after fracture test (Minitab Software V.16, State College, PA, USA). $P<0.05$ was considered to be statistically significant in all tests.

\section{Results}

Two specimens showed crack lines in the ceramic after the thermocycling process. Since no delamination or debonding occurred, these specimens were not excluded from the fracture strength test.

Group means nearly reached statistical significance as determined by one-way ANOVA $(F(4,45)=2.31, p=0.072)$ but consequently post-hoc tests were not performed. Mean fracture strength $(\mathrm{N})$ per group in descending order was as follows:

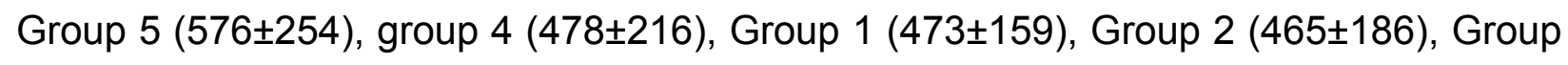
$3(314 \pm 137)$ (Table 2). The presence of complete dentin exposure sealed with DDS 
after 2 weeks on the bonded surface (Group 3) resulted in considerable lower fracture strength results, particularly when compared to group 5.

Weibull distribution presented higher shape (0) for Group 1 (3.67), than those of other groups (2.51-2.89) (Fig. 3).

Failure types were predominantly adhesive failure between the cement and the laminate veneer in Groups 1, 2, 4 whereas Group 3 presented more often complete adhesive failures between the cement and dentin (Fig. 4). In Group 5 with total exposure of dentin and sealing with IDS, failures showed some IDS and cement with or without ceramic fracture attached on the tooth. SEM images clearly showed detachment of cement from dentin surfaces in Type IV failure types with cement plugs in the dentin tubuli (Figs. 5a-b) and intact dentin-IDS-cement interface (Figs. 5c-e)

\section{Discussion}

The strength of glass matrix ceramic restorative materials rely highly on the adhesion of resin cement both to the intaglio surfaces of the ceramic restorations and the dental tissues be it enamel, dentin or a combination of them both [22]. In previous in vivo studies, different types of failures were described for ceramic laminate veneers but the most commonly observed failure types were reported as the cohesive fracture of the ceramic, followed by adhesive failures and failures of the marginal integrity [5,23-25]. Debonding of the adhesive layer from the dentin seems to be the weakest link at the dentin-cement interface in bonded restorations [13,24-28]. Accordingly, IDS is increasingly being applied as an alternative to DDS in order to minimize postoperative sensitivity and debonding of bonded restorations in dentistry. Their function, especially for ceramic laminate veneers of which their durability relies solely on adhesion of toothcement-ceramic complex, is unspecified. For this reason, this study was undertaken in order to compare the fracture strength of laminate veneers with and without IDS 
application in situations, where substrate material was only enamel, dentin or partially dentin. Based on the results of this study, since there was significant difference between the experimental groups in terms of fracture strength and failure types, and that application of IDS on dentin delivered significantly higher fracture strength results than those of the other groups and especially to DDS on dentin, the hypothesis that the presence of IDS would contribute to a higher fracture strength of the laminate veneer compared to conventional adhesive cementation (DDS) could be partly accepted.

In Group 5 where the highest results (576 N) were obtained, IDS was applied on the complete dentin surfaces, providing that the preparation outline was in enamel in all groups. Although the same preparation type was employed, mean fracture strength (314 N) was lower in Group 3 with the DDS method. These results are in agreement with other in vitro studies on adhesion in which the application of IDS also yielded to higher bond strength results than the DDS application $[11,14,15,29,30]$. Using shear test method, Bertschinger et al. [11] concluded that the "dual bonding technique" (IDS) method resulted in bond strengths (16.3 - $19 \mathrm{MPa})$ being higher than DDS method (0.3 14.9 MPa). In another study, this time using shear test method, Paul and Schärer [12] concluded that IDS increased bond strength to dentin twofold compared to DDS. Likewise, using microtensile test method, IDS method with the same adhesive resin used in this study (Optibond FL) resulted in significantly higher results (59.1 - 66.6 MPa) compared to DDS (11.6 MPa) [14]. Higher bond strength results by the application of IDS may be explained by the optimal adhesion to freshly prepared dentin that is not exposed to any contamination through the temporary cement used for the provisional restoration [10].

In this study, it was also of interest to investigate whether the amount of exposed dentin on the substrate surface had an impact on the fracture strength of laminate veneers. Former studies showed that removal of only $0.5 \mathrm{~mm}$ in the cervical area could 
already result dentin exposure [1,2]. Dentin exposure, is mostly seen in the cervical area of the preparation and contains often a quarter of the entire labial preparation surface [3]. Thus, it was suggested that preparations having enamel between 50 to $70 \%$ on the entire tooth surface would ensure durable adhesion [31,32]. Built on this statement, in our study, $1 / 4$ dentin exposure was considered as the critical amount of dentin during preparations. Yet, the amount for dentin did not significantly affect the mean fracture strength, therefore the second hypothesis could be partially accepted. In this in vitro study, the cervical margin ended in enamel. This will probably have an influence on the fracture strength compared when the cervical preparation margin ended in dentin.

It is not an easy task to state whether the obtained results in this study would sustain chewing forces. The average bite forces in human range between 20 and 1000 $\mathrm{N}$ but during actual chewing, the forces do not exceed $270 \mathrm{~N}$ [33]. Furthermore, the forces in the anterior region of the mouth are reported to be less than in the posterior region ranging between 155 and $200 \mathrm{~N}$. The fracture strengths in this study varied between minimum 200 and maximum 1006 N. Consequently, the obtained results fall under this range. However, patients with signs of bruxism express higher masticatory forces. Thus, large excessive preparations in dentin cannot be recommended without IDS, as these forces were significantly lower $(314 \pm 137 \mathrm{~N})$ than the ones with IDS $(576 \pm 254 \mathrm{~N})$. Nonetheless, considering the Weilbull parameters, characteristics of adhesion still seems to be the most reliable when ceramic laminate veneers were bonded onto surfaces entirely in enamel supported by the lower variability of data compared to dentin exposure with varying amounts with and without IDS or DDS. This aspect needs to be verified in higher number of specimens in future studies.

In addition to fracture strength results, analysis of the failures also provide important information. While in Group 3 in which DDS was applied on the preparation entirely in 
dentin showed mainly adhesive failures between cement and dentin, in Group 5 where IDS was applied on the preparation entirely in dentin, showed less adhesive failures. In other words, the use of IDS layer decreased the amount of adhesive failures at the cement-dentin interface. Similarly, according to SEM findings, cement-dentin interface was the weakest link even in the IDS applied specimens.

The adhesive failures from dentin accompanied with low fracture strength results such as in Group 3 can be explained by the theory that during the application of the composite cement and veneers, the pressure could have collapsed the collagen network [14,34]. The polymerized adhesive resin (IDS) of Group 5 with full infiltration into the hybrid layer could have prevented the collapse of the dentinal collagen structure $[13,14,34,35]$. Furthermore, water sorption could also decrease adhesive strength, as improper infiltration of the collagen network by the adhesive resin would result in hydrolytical degradation and decrease resin-resin adhesion [36]. Most failures of ceramic laminate veneers were observed at the adhesive interface of the substrate where the highest tensile forces are observed [37]. Due to placement of the load cell at the incisal area, stress concentration was concentrated at the interface but when adhesive strength is sufficient, the failure occurs cohesive in the ceramic itself. Report of clinical failures and their location should verify these findings.

In this study, an interaction was observed between the IDS layer and the provisional veneer material (Protemp). The provisional veneers placed on the IDS applied groups were more difficult to remove compared with the control and DDS applied groups. The presence of flaws in the IDS layer of all specimens was analyzed with the aid of microscopy and IDS layer was found to be still intact after the removal of the provisional veneers. In fact, IDS was isolated using glycerine gel. This aspect has not been studied in the dental literature but most probably, polymerization inhibited layer of IDS layer with the glycerine and cleaning with pumice was not sufficient. Thus, air-blocking with 
glycerine gel did not eliminate the oxygen inhibition layer completely [38]. The interaction and difficult removal of the provisional could be attributed to this phenomenon [39].

All specimens in this study were aged by means of thermocycling. Due to this aging process, the interface between the composite matrix and the silica coated inorganic fillers were expected to hydrolytically degrade mainly at the adhesive interface [36]. This aging method was performed to mimic the oral conditions with intraoral temperature alterations by intake of food and beverages. This method has been used in many in vitro studies, however published reports on thermocycling are contradictory. In a metaanalysis thermocycling showed no significant effect on mean shear bond strength between 9.6 (no thermocycling) and 10.3 MPa (with thermocycling) [40]. Thus, the guidelines of ISO requiring 500 cycles may not be sufficient to have an aging especially in specimens prepared for macroshear bond tests $[41,42]$. This could apply also to the large area in bonded laminate veneers. However, it has to be emphasized that in this study internal cracks were observed in the ceramic in two specimens after thermocycling, indicating that some kind of aging took place in the ceramic. Since there was no delamination or cohesive fractures both specimens were not excluded in the fracture test. The internal crack lines due to thermocycling did not show influence the on ultimate strength of these specimens. However, the effect of aging parameters at longer durations on the long-term stability of IDS and DDS should be studied in future studies.

\section{Conclusions}

From this study, the following could be concluded:

1. When ceramic laminate veneers are bonded to large surfaces of exposed dentin, application of an immediate dentin sealing improves the adhesion and thereby 
the fracture strength of veneers. Small areas of dentin exposure less than $1 / 4$ of the bonding surface did not benefit from IDS application.

2. Considering Weilbull parameters, characteristics of adhesion seems to be the most reliable when ceramic laminate veneers are bonded onto surfaces entirely in enamel compared to dentin exposure with varying amounts with and without IDS or DDS.

\section{Acknowledgements}

The authors acknowledge Mr. Stephan van der Made, Kwalident Dental Laboratory, Beilen, The Netherlands, for his meticulous work in fabricating the ceramic laminate veneers, and extend their gratitude to Ivoclar Vivadent, Schaan, Liechtenstein and Kerr, Orange, CA, USA for generous provision of some of the materials used in this study.

\section{References}

[1] Ferrari M, Patroni S, Balleri P. Measurement of enamel thickness in relation to reduction for etched laminate veneers. Int J Periodont Rest Dent 1992;12:407-13. 
[2] Nattress BR, Youngson CC, Patterson CJ, Martin DM, Ralph JP. An in vitro assessment of tooth preparation for porcelain veneer restorations. J Dent 1995;23:16570.

[3] Cherukara GP, Davis GR, Seymour KG, Zou L, Samarawickrama DY. Dentin exposure in tooth preparations for porcelain veneers: a pilot study. J Prosthet Dent 2005;94:414-20.

[4] Chun YH, Raffelt C, Pfeiffer H, Bizhang M, Saul G, Blunck U, Roulet JF. Restoring strength of incisors with veneers and full ceramic crowns. J Adhes Dent 2010;12:45-54.

[5] Friedman MJ. A 15-year review of porcelain veneer failure-a clinician's observations. Compend Contin Educ Dent 1998;19:625-28.

[6] Dumfahrt H, Schäffer H. Porcelain laminate veneers. A retrospective evaluation after 1 to 10 years of service: Part II-clinical results. Int J Prosthodont 2000;13:9-18.

[7] Peumans M, Munck de J, Fieuws S, Lambrechts P, Vanherle G, Van Meerbeek B. A prospective ten-year clinical trial of porcelain veneers. J Adhes Dent 2004;6:65-76.

[8] Guess PC, Stappert FJ. Midterm results of a 5-year prospective clinical investigation of extended ceramic veneers. Dent Mater 2008;24:804-13.

[9] Burke FJ. Survival rates for porcelain laminate veneers with special reference to the effect of preparation in dentin: a literature review. J Esthet Restor Dent 2012;24:257-65.

[10] Pashley EL, Comer RW, Simpson MD, Horner JA, Pashley DH, Caughman WF. Dentin permeability: sealing the dentin in crown preparations. Oper Dent 1992;17:13-20.

[11] Bertschinger C, Paul SJ, Luthy H, Scharer P. Dual application of dentin bonding agents: effect on bond strength. Am J Dent 1996;9:115-9. 
[12] Paul SJ, Scharer P. The dual bonding technique: a modified method to improve adhesive luting procedures. Int J Periodont Restor Dent 1997;17:536-45.

[13] Magne P, Douglas WH. Porcelain veneers: dentin bonding optimization and biomimetic recovery of the crown. Int J Prosthodont 1999;12:111-21.

[14] Magne P, So WS, Cascione D. Immediate dentin sealing supports delayed restoration placement. J Prosthet Dent 2007;98:166-74.

[15] Lee Jl. Park SH. The effect of three variables on shear bond strength when luting a resin inlay to dentin. Oper Dent 2009;34:288-92.

[16] Duarte S,Jr, de Freitas CR, Saad JR, Sadan A. The effect of immediate dentin sealing on the marginal adaptation and bond strengths of total-etch and self-etch adhesives. J Prosthet Dent 2009;102:1-9.

[17] Reis A, Rocha de Oliveira Carrilho M, Schroeder M, Tancredo LL, Loguercio $A D$. The influence of storage time and cutting speed on microtensile bond strength. $J$ Adhes Dent 2004;6:7-11.

[18] Magne P. Immediate dentin sealing: a fundamental procedure for indirect bonded restorations. J Esthet Restor Dent 2005;17:144-54.

[19] Dietschi D, Monasevic M, Krejci I, Davidson C. Marginal and internal adaptation of class II restorations after immediate or delayed composite placement. J Dent 2002;30:259-69.

[20] Gresnigt MMM, Özcan M, Kalk W, Galhano G. Effect of static and cyclic loading on ceramic laminate veneers adhered to teeth with and without aged composite restorations. J Adhes Dent 2011;13:569-77.

[21] Gresnigt MMM, Kalk W, Özcan M. Clinical longevity of ceramic laminate veneers bonded to teeth with and without existing composite restorations up to 40 months. Clin Oral Investig 2013;17:823-32. 
[22] Peumans M, Van Meerbeek B, Lambrechts P, Vanherle G. Porcelain veneers: a review of the literature. J Dent 2000;28:163-77.

[23] Friedman M. Multiple potential of etched porcelain laminate veneers. J Am Dent Assoc 1987;83E-87E.

[24] Peumans M, De Munck J, Fieuws S, Lambrechts P, Vanherle G, Van Meerbeek B. A prospective ten-year clinical trial of porcelain veneers. J Adhes Dent 2004;6:65-76.

[25] Beier US, Kapferer I, Burtscher D, Dumfahrt H. Clinical performance of porcelain laminate veneers for up to 20 years. Int J Prosthodont 2012;25:79-85.

[26] Van Meerbeek B, Peumans M, Gladys S, Braem M, Lambrechts P, Vanherle G. Three-year clinical effectiveness of four total-etch dentinal adhesive systems in cervical lesions. Quintessence Int 1996;27:775-84.

[27] Van Meerbeek B, Perdigao J, Lambrechts P, Vanherle G. The clinical performance of adhesives. J Dent 1998;26:1-20.

[28] De Munck J, Van Landuyt K, Peumans M, Poitevin A, Lambrechts P, Braem M, Van Meerbeek B. A critical review of the durability of adhesion to tooth tissue: methods and results. J Dent Res 2005;84:118-32.

[29] Cagidiaco MC, Ferrari M, Garberoglio R, Davidson CL. Dentin contamination protection after mechanical preparation for veneering. Am J Dent 1996;9:57-60.

[30] Magne P, Kim TH, Cascione D, Donovan TE. Immediate dentin sealing improves bond strength of indirect restorations. J Prosthet Dent 2005;9:511-9.

[31] Cherukara GP, Davis GR, Seymour KG, Zou L, Samarawickrama DY. Dentin exposure in tooth preparations for porcelain veneers: a pilot study. J Prosthet Dent 2005;94:414-20.

[32] Chiche GJ, Pinault A. Esthetics of anterior fixed prosthodontics Chicago: Quintessence Publishing Co; 1994, p. 20-24. 
[33] Naeije M, Loon LAJ. Craniomandibulaire functie en disfunctie.: Bohn Stafleu Van Loghum;1998:39-56.

[34] Breschi L, Mazzoni A, Ruggeri A, Cadenaro M, Di Lenarda R, De Stefano Dorigo E. Dental adhesion review: aging and stability of the bonded interface. Dent Mater 2008;24:90-101.

[35] Dietschi D, De Siebenthal G, Neveu-Rosenstand L, Holz J. Influence of the restorative technique and new adhesives on the dentin marginal seal and adaptation of resin composite Class II restorations: an in vitro evaluation. Quintessence Int 1995;26:717-27.

[36] Özcan M, Barbosa SH, Melo RM, Galhano GA, Bottino MA. Effect of surface conditioning methods on the microtensile bond strength of resin composite to composite after aging conditions. Dent Mater 2007;23:1276-82.

[37] Magne P, Kwon KR, Belser UC, Hodges JS. Douglas WH. Crack propensity of porcelain laminate veneers: A simulated operatory evaluation. J Prosthet Dent 1999;81:327-34.

[38] Magne P, Nielsen B. Interactions between impression materials and immediate dentin sealing. J Prosthet Dent 2009;102:298-305.

[39] Endo T, Finger WJ, Hoffmann M, Kanehira M, Komatsu M. The role of oxygen inhibition of a self-etch adhesive on self-cure resin composite bonding. Am J Dent 2007;20:157-60.

[40] Leloup G, D'Hoore W, Bouter D, Degrange M, Vreven J. Meta-analytical review of factors involved in dentin adherence. J Dent Res 2001;80:1605-14.

[41] Gale MS, Darvell BW. Thermal cycling procedures for laboratory testing of dental restorations. J Dent 1999;27:89-99. 
[42] De Munck J, Mine A, Poitevin A, Ende A, Cardoso MV, Van Landuyt KL, Peumans M, Van Meerbeek B. Meta-analytical review of parameters involved in dentin bonding. J Dent Res 2012;91:351-7.

\section{Captions to tables and figures:}

\section{Tables:}

Table 1. The brands, types, chemical compositions, manufacturers and batch numbers of the materials used for the experiments.

Table 2. Fracture strength results (Mean \pm standard deviation) (Newton) of experimental groups, minimum, maximum and Confidence Intervals (95\%). For Group descriptions see Fig. 1.

\section{Figures:}


Fig. 1. Flow-chart showing experimental sequence and allocation of groups.

Fig. 2. The position of the load cell in relation to the laminate veneer-tooth interface in the universal testing machine where loading was applied until fracture.

Fig. 3. Probability plot with Weibull curves $(95 \% \mathrm{Cl})$ using maximum likelihood estimation, scale and shape values for all groups.

Fig. 4 Frequencies of failure modes in percentages. Type I: Cohesive ceramic fracture; Type II: Adhesive failure between the cement and ceramic; Type III: Adhesive failure between the cement and enamel; Type IV: Adhesive failure between the cement/IDS and dentin; Type V: Adhesive failure between the IDS and cement; Type VI: Tooth fracture.

Figs. 5a-e. a) Typical Type IV failure from a specimen in Group 3 and b) the corresponding SEM image ( $x$ 5000). Note cement plugs in the dentin tubuli after detachment of the laminate veneer; c) Typical Type IV failure from a specimen in Group 5 with total exposure of dentin and sealing with IDS, and d) the corresponding SEM image ( $x 5000$ ) with or e) without ceramic fracture attached on the tooth. Note the intact dentin-IDS-cement interface (K: Ceramic, C: Cement and IDS, D: Dentin, I: IDS) (x500). 
Tables:

\begin{tabular}{|c|c|c|c|c|}
\hline Materials & Type & Chemical Composition & Manufacturer & $\begin{array}{l}\text { Batch } \\
\text { umber }\end{array}$ \\
\hline Total-etch & Etching agent & $37 \%$ Phosphoric acid & $\begin{array}{c}\text { Ivoclar Vivadent, } \\
\text { chaan, Liechtenstein }\end{array}$ & P14739 \\
\hline OptiBond FL & Adhesive resin & $\begin{array}{l}\text { Primer: Hydroxyethyl } \\
\text { ethacrylate, Glycerolphophate } \\
\text { methacrylate, phathalic acid } \\
\text { onoethyl methacrylate, ethanol, } \\
\text { ater, photo-initiator } \\
\text { Adhesive: Triethylene glycol } \\
\text { methacrylate, Urethane } \\
\text { methacrylate, Glycerolphophate } \\
\text { methacrylate, Hydroxyethyl } \\
\text { ethacrylate, bis-phenol A glycol } \\
\text { methacrylate, filler, photo initiator }\end{array}$ & $\begin{array}{l}\text { Kerr, Orange, CA, } \\
S A\end{array}$ & 3661962 \\
\hline ESPE-Sil & $\begin{array}{l}\text { Silane coupling } \\
\text { yent }\end{array}$ & $\begin{array}{l}\text { Ethyl alcohol, } \\
\text { ethacryloxypropyl, trimethoxysilane }\end{array}$ & $\begin{array}{l}\text { 3M ESPE, St. Paul, } \\
\text { innesota, USA }\end{array}$ & 1311011 \\
\hline $\begin{array}{l}\text { IPS Empress } \\
\text { ching gel }\end{array}$ & Ceramic etching & $<5 \%$ Hydrofluoric acid & Ivoclar Vivadent & P14739 \\
\hline CoJet-Sand & $\begin{array}{l}\text { One component } \\
\text { imer }\end{array}$ & $\begin{array}{l}\text { Aluminium trioxide } \\
\text { pated with silica, particle } \\
n\end{array}$ & 3M ESPE & 442859 \\
\hline $\begin{array}{l}\text { Monobond } \\
\text { us }\end{array}$ & & $\begin{array}{l}\text { Ethanol, 3- } \\
\text { methoxysilsylpropylmethacrylate, } \\
\text { ethacrylated phosphoric acid ester }\end{array}$ & Ivoclar Vivadent & N37750 \\
\hline $\begin{array}{l}\text { Syntac } \\
\text { imer }\end{array}$ & Primer & $\begin{array}{l}\text { Water, acetone, maleic acid, } \\
\text { methacrylate }\end{array}$ & Ivoclar Vivadent & P17329 \\
\hline $\begin{array}{l}\text { Syntac } \\
\text { dhesive }\end{array}$ & Adhesive resin & $\begin{array}{l}\text { Water, gluteraldehyde, maleic } \\
\text { id, poly-ethyleneglycodi- } \\
\text { ethacrylate }\end{array}$ & Ivoclar Vivadent & P15364 \\
\hline Heliobond & Adhesive resin & $\begin{array}{l}\text { bis-phenol A glycol } \\
\text { methacrylate, dimethacrylate, } \\
\text { itiators and stabilizers }\end{array}$ & Ivoclar Vivadent & P06157 \\
\hline $\begin{array}{l}\text { Variolink } \\
\text { eneer }\end{array}$ & $\begin{array}{c}\text { Light curing resin } \\
\text { ment (Medium Value }\end{array}$ & $\begin{array}{l}\text { Urethane dimethacrylate, } \\
\text { organic fillers, ytterbium trifluoride, } \\
\text { itiators, stabilizers, pigments }\end{array}$ & Ivoclar Vivadent & N64556 \\
\hline
\end{tabular}

Table 1. The brands, types, chemical compositions, manufacturers and batch numbers of the materials used for the experiments. 


\begin{tabular}{|c|c|c|c|c|c|c|}
\hline $\begin{array}{c}\text { Experimenta } \\
\text { I Groups }\end{array}$ & $\mathbf{n}$ & Mean (SD) & Minimum & Maximum & \multicolumn{2}{|c|}{ Confidence Interval } \\
\cline { 5 - 7 } & 10 & $473 \pm 159$ & 200 & 645 & 358.9 & 586.4 \\
\hline $\mathbf{1}$ & 10 & $465 \pm 186$ & 230 & 768 & 332.2 & 597.6 \\
\hline $\mathbf{2}$ & 10 & $314 \pm 137$ & 172 & 637 & 216.4 & 412.5 \\
\hline $\mathbf{3}$ & 10 & $478 \pm 216$ & 248 & 900 & 323.6 & 632.7 \\
\hline $\mathbf{4}$ & 10 & $576 \pm 254$ & 269 & 1006 & 393.8 & 757.7 \\
\hline $\mathbf{5}$ & & & & & & \\
\hline
\end{tabular}

Table 2. Fracture strength results (Mean \pm standard deviation) (Newton) of experimental groups, minimum, maximum and confidence Intervals (95\%). For group descriptions see Fig. 1. 


\section{Figures:}

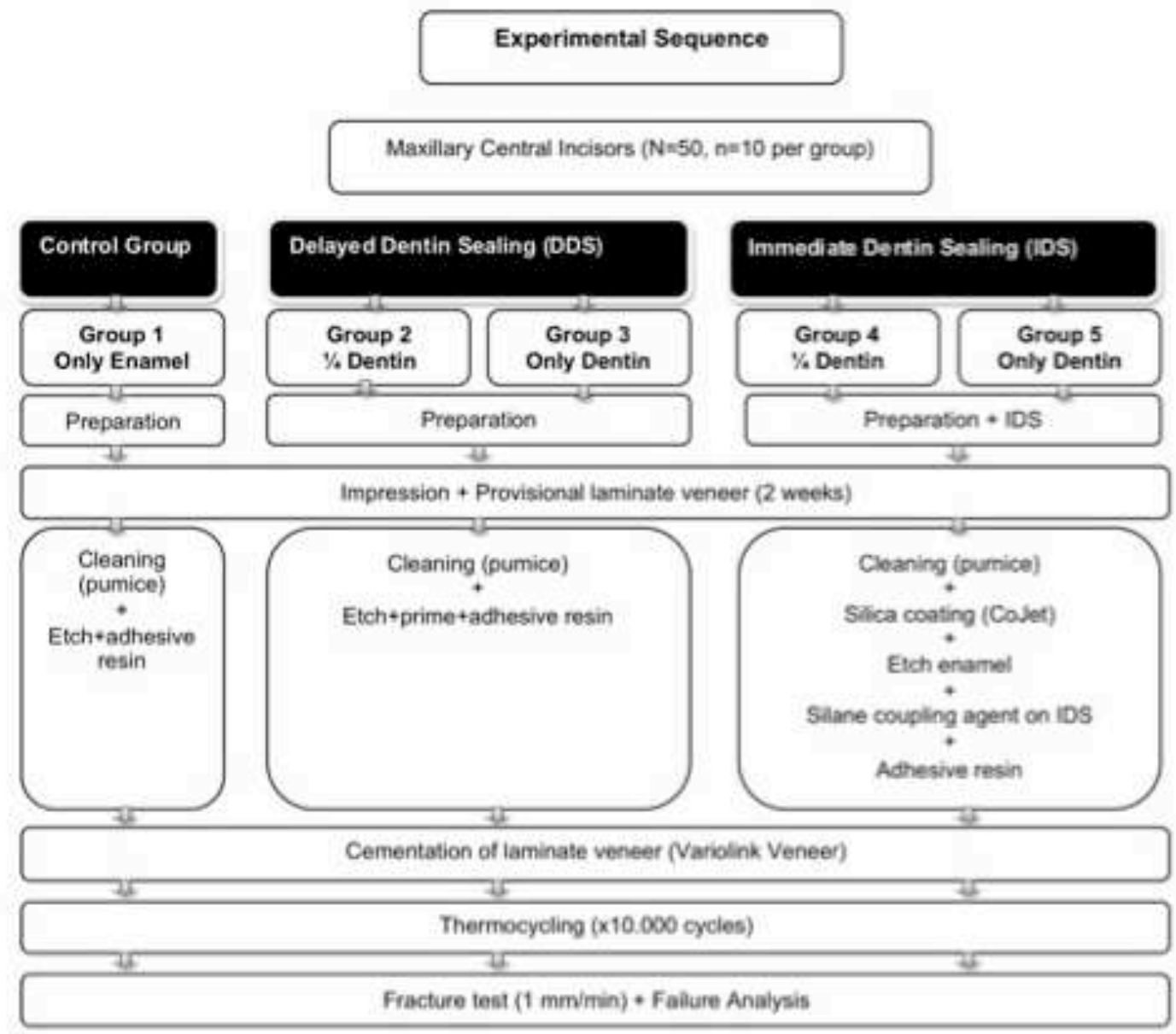

Fig. 1. Flow-chart showing experimental sequence and allocation of groups.

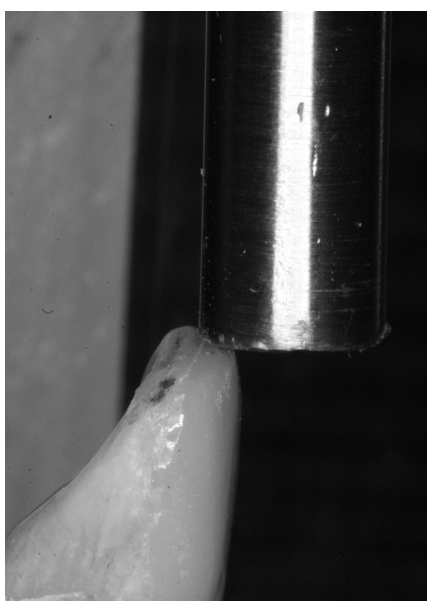

Fig. 2. The position of the load cell in relation to the laminate veneer-tooth interface in the universal testing machine where loading was applied until fracture. 


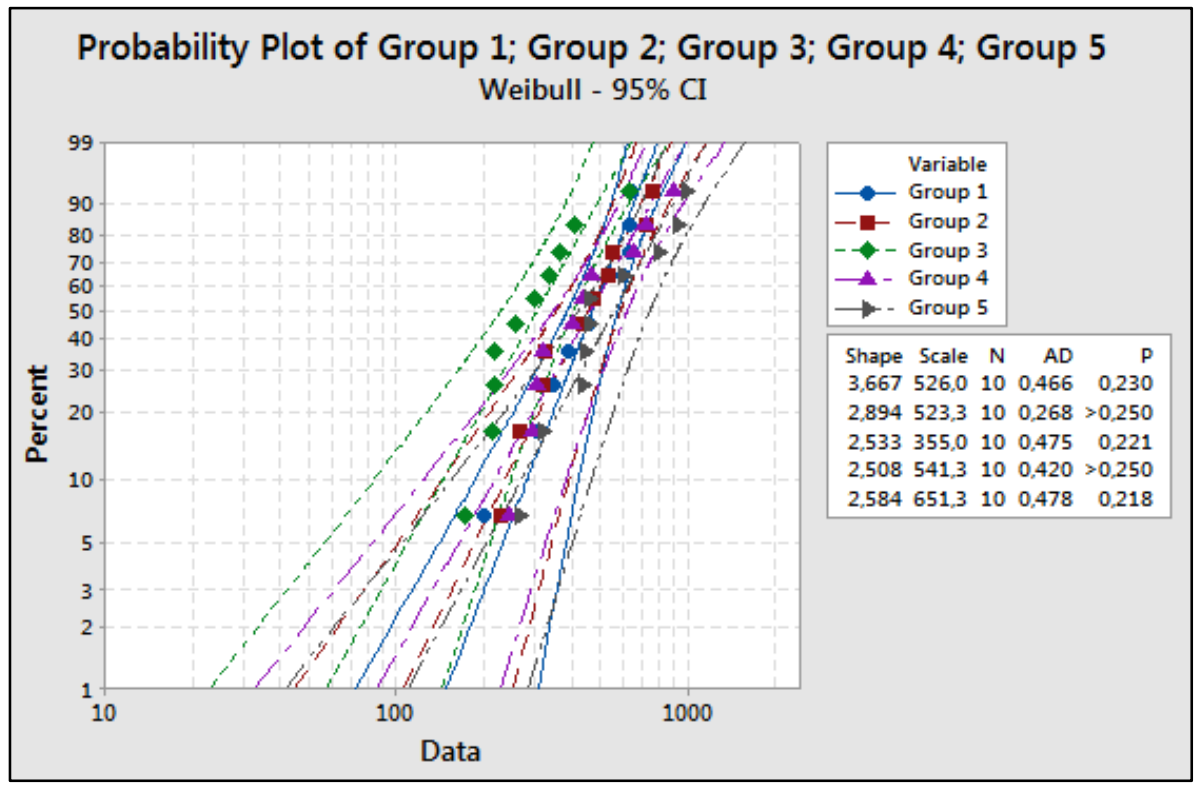

Fig. 3. Probability plot with Weibull curves $(95 \% \mathrm{Cl})$ using maximum likelihood estimation, scale and shape values for all groups.

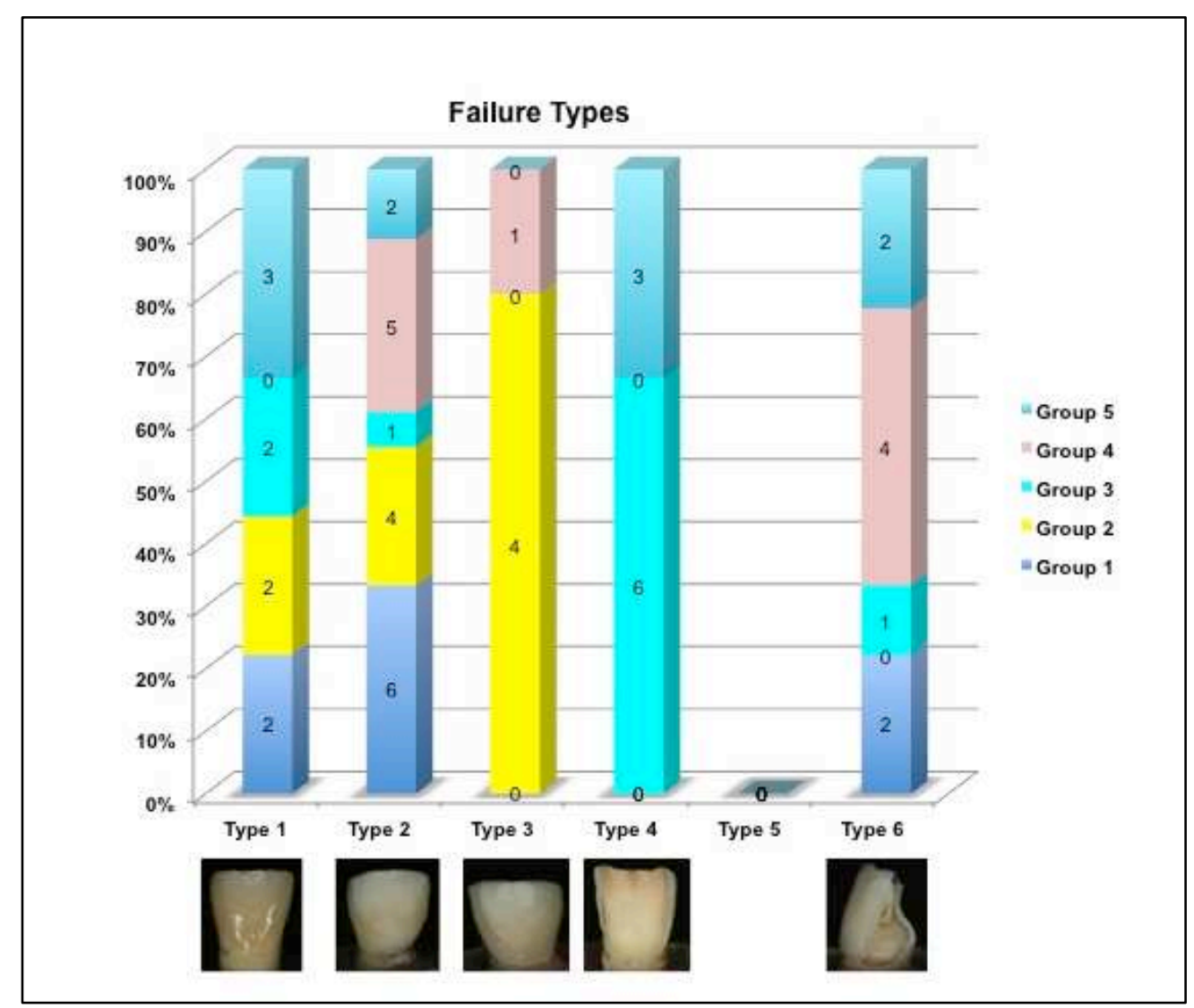

Fig. 4 Frequencies of failure modes in percentages. Type I: Cohesive ceramic fracture; Type II: Adhesive failure between the cement and ceramic; Type III: Adhesive failure between the cement and enamel; Type IV: Adhesive failure between the cement/IDS and dentin; Type V: Adhesive failure between the IDS and cement; Type VI: Tooth fracture. 


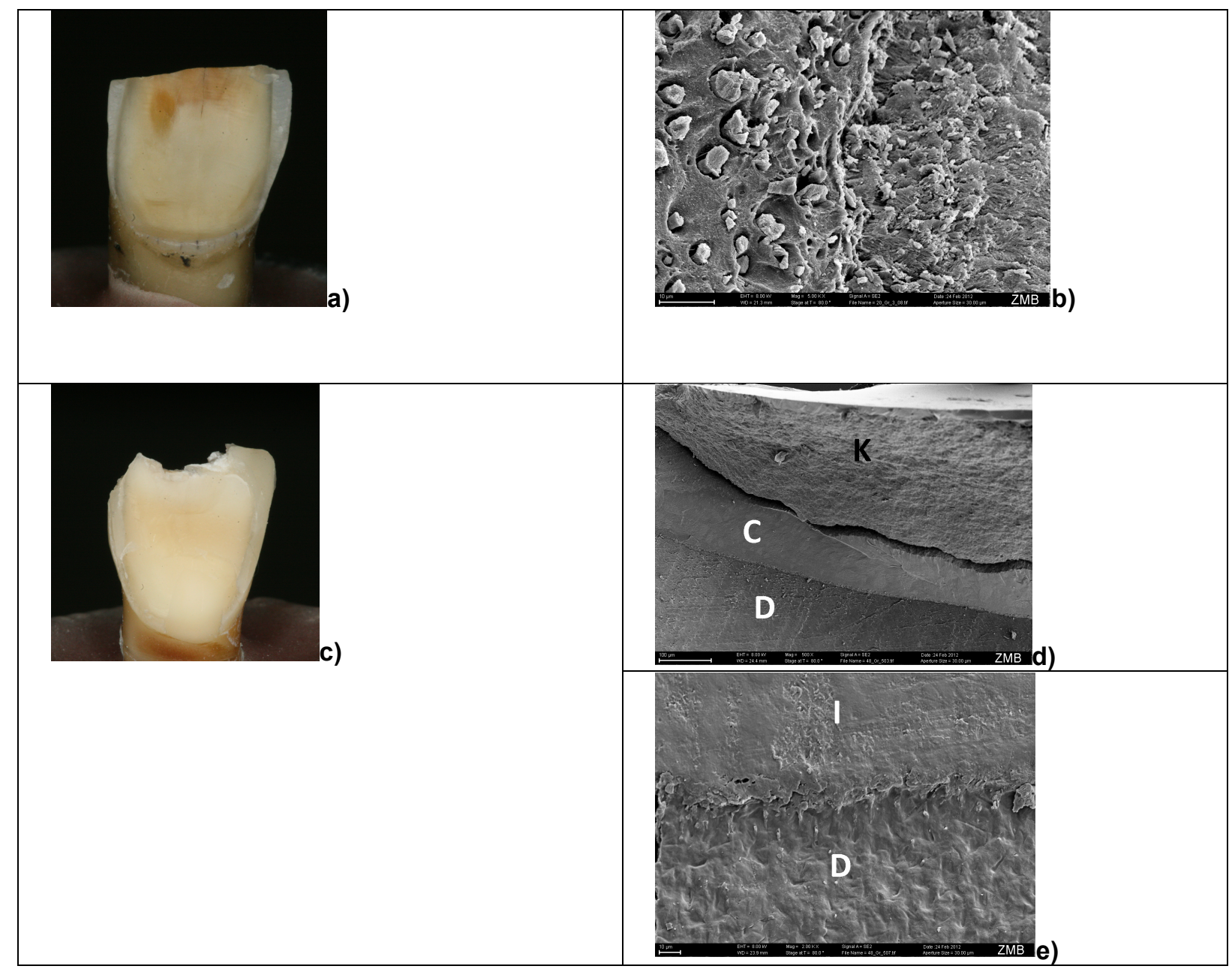

Figs. 5a-e. a) Typical Type IV failure from a specimen in Group 3 and b) the corresponding SEM image (x 5000). Note cement plugs in the dentin tubuli after detachment of the laminate veneer; c) Typical Type IV failure from a specimen in Group 5 with total exposure of dentin and sealing with IDS, and d) the corresponding SEM image (x 5000) with or e) without ceramic fracture attached on the tooth. Note the intact dentin-IDS-cement interface (K: Ceramic, C: Cement and IDS, D: Dentin, I: IDS) (x500). 